\title{
Presentación del Dosier
}

El Pentateuco es un patrimonio cultural de la humanidad. El mundo narrado en él pertenece al segundo milenio antes de Cristo, y las narraciones, poemas y conjuntos de leyes contenidos en él fueron compuestos durante los primeros seis siglos del primer milenio antes de Cristo. Por un lado, al reunir poesía épica, lírica y legal, los ciento ochenta y siete capítulos constituyen, en forma de cinco libros, una obra maestra en la historia de la literatura. Por otro lado, es la literatura la que propone cultivar la memoria, ya sea en relación con el mundo narrado, o en vista del período de su compositor, a veces narrando, a veces legislando, a veces cantando. Además, como literatura dirigida a la historia, los textos del Pentateuco promueven una enorme reflexión teológica. El objetivo principal parece ser pensar en Dios. Así, los primeros cinco libros de la Biblia judía y la Biblia cristiana, con sus modelos narrados de fe y comportamiento, convertidos en poemas y definidos por formulaciones legales, se convirtieron en la referencia fundamental para la religión del antiguo Israel, de donde nació el judaísmo y, de este último, el cristianismo. También Jesús de Nazaret, en los cuatro Evangelios del Nuevo Testamento, se presenta en relación con Abraham y Moisés, y se destaca como un maestro único con respecto a las leyes contenidas en el Pentateuco.

En vista de esta importancia, está claro que cualquier estudio más serio de la fe judía y cristiana, como los cursos universitarios de Teología y/o los programas de estudios posgrado en Teología o Ciencias de la Religión, tiene la intención de hacerlo participar en investigaciones sobre lo que escucha o lee en el Pentateuco. ${ }^{1}$ Además, el Pentateuco también debe ganar espacio para estudiar literatura, filosofía, historia, sociología, etc. O, en otras palabras: quien estudia el Pentateuco, después de haber adquirido esta nueva competencia, necesita ponerse al servicio de diversas ciencias, comunidades religiosas y la sociedad en general. Por lo tanto, todas las personas, así como las sociedades y toda la humanidad, están en peligro de necesitar sabiduría, algo de mayor importancia en vista de la

MANZATTO, Antonio; GRENZER, Matthias. Teologia cristã latino-americana. Anotações sobre a Área de Concentração do Programa de Estudos Pós-Graduados em Teologia da PUC-SP. Revista de Cultura Teológica, n. 89, p. 27-53, 2018. 
supervivencia digna de todos. El Pentateuco, a su vez, es capaz de impartir sabiduría inigualable.

Los estudios, a su vez, requieren un método. ${ }^{2}$ En las últimas décadas, el número de estudios detallados dedicados a la investigación sincrónica del texto final del Pentateuco ha aumentado. La configuración poética se redescubre y, por lo tanto, la calidad literaria del texto encontrado por los oyentes-lectores en la Biblia, que es el texto canonizado. También está dirigido a la reflexión teológica, que se ve favorecida por la belleza que pertenece a los textos bíblicos como literatura. Ciertos elementos textuales, que en estudios diacrónicos se habían evaluado como signos de múltiples ensayos, por ejemplo, repeticiones, se explican como elementos estilísticos intencionales y planificados empleados por el propio autor para resaltar, de manera artística y/o retórica, lo que era más importante para él. Ciertamente, no se niega en el mundo de la investigación que el Pentateuco sea el resultado de procesos complejos de escritura, escritura y compilación de textos que tuvieron lugar en diferentes momentos. Por lo tanto, el estudio diacrónico siempre estará bien justificado. Sin embargo, queda la pregunta de si estos procesos aún pueden aclararse en detalle. En este sentido, la falta de un mayor consenso entre los investigadores sobre sus propios resultados es bastante significativa.

En este Dosier sobre la "Exégesis del Pentateuco", presentado por la revista Caminhando, se mezclan los estudios sincrónicos y diacrónicos. Tales estudios son, sobre todo, resultados de investigaciones de miembros del Grupo de Investigación de Traducción e Interpretación del Antiguo Testamento (TIAT). Sobre todo, se investigan extractos o episodios más pequeños, e incluso microunidades literarias, sabiendo que comprender un detalle puede ser significativo en vista de un acercamiento más cercano a todo el trabajo del Pentateuco. Además, también hay en este Dosier investigación temática dirigida al estudio de cargas semánticas de ciertas palabras y/o intertextualidades.

El primer estudio, de Matthias Grenzer y Luciano José Dias, tiene como objetivo el análisis poético y/o lingüístico-literario del discurso del Señor Dios de Israel, en Ex 34,6c-7d. Es decir, la investigación se centra exclusivamente en la forma dada a los siete versículos en cuestión aquí, para comprender mejor la fuerza retórica que pertenece al discurso divino.

2 De forma atualizada, a história da interpretação do Pentateuco pode ser conferida em: Féliz GARCÍA LÓPEZ. Pentateuco: introducción a la lectura de los cinco primeros libros de la Biblia. 2. ed. revisada y actualizada. Estella, 2014, p. 45-76. 
El segundo estudio de Valmor da Silva y Joilson de Souza Toledo “"Me acercaré y veré esta cosa extraña' (Éxodo 3,3): una traducción de la Biblia y sus posibilidades hermenéuticas" - se centra principalmente en la traducción de una palabra hebrea y las diversas posibilidades de traducción reflejan las posibilidades de comprensión inherentes al texto bíblico.

El tercer estudio, de Leonardo Agostini Fernandes, presenta un conjunto más amplio de versos. Apunta a la escena del Ex 3,1-6 y la reflexión teológica promovida por esta micronarrativa.

El cuarto estudio, de Petterson Brey, acoge, a través del tema de la migración humana, un tema más actual, que apunta, sobre todo, a la perspectiva favorecida por la narrativa exodal sobre la legitimidad del poder.

También el quinto estudio, de Telmo José Amaral de Figueiredo, está dedicado a la exégesis del libro del Éxodo. Esta vez, sin embargo, el enfoque recae en las formulaciones legales del Código de la Alianza en el Ex 20,22-3,33, especialmente en cómo los pobres llaman la atención en este conjunto de leyes.

Una vez más, el sexto estudio, realizado por Ulises Quintão de Carvalho y Valeriano dos Santos Costa, lleva a cabo una investigación en vista de las tradiciones legales. Esta vez, las leyes sobre la construcción del santuario en el desierto están en juego y cómo, aparentemente, se incluye un modelo cosmológico en la configuración del espacio sagrado.

También el séptimo estudio, de Gilvan Leite de Araújo, está dedicado al santuario del desierto. Sin embargo, en vista de una intertextualidad, estudiamos cómo la reflexión puede ir del santuario del desierto al santuario del cuerpo de Jesús (Jn 2,13-22).

Finalmente, esperamos que la investigación presentada en este Dosier sea una contribución válida a la exégesis del Pentateuco en Brasil y América Latina. En el continente en el que nació una Teología, que se inspiró sobre todo en la narrativa exodal, capaz de atraer la atención de cristianos y no cristianos en todo el mundo, los estudios del Pentateuco deben avanzar, para que los fundamentos bíblicos estén disponibles para quienes proponen para reflexionar sobre Dios.

Prof. Dr. Matthias Grenzer Pontificia Universidade Católica de São Paulo (PUC-SP) 
